\title{
Independent Expression of Synaptic and Morphological Plasticity Associated with Long-Term Depression
}

\author{
Xiao-bin Wang, Yunlei Yang, and Qiang Zhou \\ Department of Neurology, Mount Sinai School of Medicine, New York, New York 10029
}

\begin{abstract}
Physiological and morphological alterations occur with long-term synaptic modifications, such as long-term potentiation (LTP) and long-term depression (LTD), but whether these two processes are independent or interactive is unclear. It is also unknown whether or how morphological modifications, like spine remodeling, may contribute to physiological modifications, such as trafficking of glutamate receptors which underlies, at least partially, the expression of LTP and LTD. In this study, we monitored spine size and synaptic responses simultaneously using combined two photon time-lapse imaging with patch-clamp recording in acute hippocampal slices. We show that spine shrinkage and LTD can occur independently of each other. We further show that changes in spine size are unrelated to trafficking of AMPA receptors (AMPARs) under various conditions: constitutive trafficking of AMPARs, insulin-induced internalization of AMPARs, or lateral movement of AMPARs to extrasynaptic sites. Induction of LTD of NMDA receptor-mediated responses (NMDAR-LTD) is associated with spine shrinkage. Nonetheless, NMDAR-LTD and spine shrinkage diverge in the downstream signaling events, and can occur independently of each other. Thus, spine shrinkage is not caused by or required for trafficking of glutamate receptors. In a broader sense, there is a clear dissociation between physiological and morphological expression of LTD. However, inhibition of actin depolymerization blocked the expression of LTD, suggesting that morphologically silent actin remodeling may be involved in the physiological expression of LTD and different subpopulations of actin filaments undergo changes during LTD.
\end{abstract}

Key words: dendritic spine; actin; long-term depression; synaptic plasticity; hippocampus; two-photon imaging

\section{Introduction}

Persistent synaptic modification is considered to underlie the developmental refinement of neural circuitry and some forms of learning and memory. Induction of long-term plasticity triggers two processes: postsynaptic modifications of AMPA receptors (AMPARs) (Malinow and Malenka, 2002; Song and Huganir, 2002; Bredt and Nicoll, 2003; Collingridge et al., 2004; Malenka and Bear, 2004), and changes in the morphology of dendritic spines (Harris, 1999; Yuste and Bonhoeffer, 2001; Nimchinsky et al., 2002; Kasai et al., 2003; Segal, 2005). During long-term potentiation (LTP) and long-term depression (LTD), the AMPAR synaptic responses, and the spine size change in parallel (Engert and Bonhoeffer, 1999; Maletic-Savatic et al., 1999; Matsuzaki et al., 2004; Nagerl et al., 2004; Zhou et al., 2004). At naive synapses, the number of synaptic AMPARs is proportional to the size of spines (Harris, 1999; Nimchinsky et al., 2002; Kasai et al., 2003), also supports the idea that physiological and morphological properties may be coregulated by common mechanisms. However, it remains to be determined whether these seemingly coor-

Received May 3, 2007; revised Aug. 31, 2007; accepted Sept. 20, 2007.

This work was supported by the Whitehall Foundation and the Ellison Medical Foundation. We thank Drs. D. L. Benson and J. H. Morrison for discussion of the results, Drs. D. L. Benson and D. J. Linden for critical comments on this manuscript, and Dr. S. L. Wearne and A. Rodriguez for help on the data analysis.

Correspondence should be addressed to Dr. Qiang Zhou, Department of Neurology, Mount Sinai School of Medicine, One Gustave Levy Place, Box 1137, New York, NY 10029. E-mail: qiang.zhou@mssm.edu.

DOI:10.1523/JNEUROSCI.2015-07.2007

Copyright $\odot 2007$ Society for Neuroscience $\quad 0270-6474 / 07 / 2712419-11 \$ 15.00 / 0$ dinated changes reflect actual interactions between these two processes.

There are two possible ways that physiological and morphological modifications can be linked: via a common signaling mechanism or coupled by a common physical process. We have shown previously that spine shrinkage and LTD both require $\mathrm{Ca}^{2+}$ influx through NMDARs and elevated calcineurin activity, but spine shrinkage lies downstream of cofilin/ADF whereas LTD requires protein phosphatase 1 (PP-1) activity (Zhou et al., 2004), suggesting that the pathways diverge. Are spine shrinkage and LTD coupled physically? With the induction of LTD, dephosphorylation and removal of AMPARs occurs. The removal of AMPARs plays a major role in the expression of LTD (Carroll et al., 2001; Malinow and Malenka, 2002; Song and Huganir, 2002; Bredt and Nicoll, 2003; Henley, 2003; Collingridge et al., 2004; Kim and Sheng, 2004; Malenka and Bear, 2004). In addition, NMDAR-mediated synaptic responses are also reduced concomitant with the depression of AMPAR responses, and activity-dependent translocation of NMDARs appears to underlie this depression (Montgomery et al., 2005; Morishita et al., 2005). It remains to be tested whether endocytosis of glutamate receptors contributes to internalization of membrane (Sheng and Lee, 2003).

In the current study, we have addressed two questions: (1) are physiological and morphological expression of LTD independent processes? (2) Is remodeling of actin cytoskeleton involved in the expression of LTD? We monitored both synaptic response and spine morphology simultaneously using combined patch-clamp 
recording and two-photon time lapse imaging in acute hippocampal slices. We show that spine shrinkage and LTD are independent processes, but morphologically silent actin remodeling is required for the expression of LTD. Thus, distinct types of actin modifications are involved in the physiological and morphological expression of LTD.

\section{Materials and Methods}

Slice preparation and recording procedure. Coronal brain sections (350 $\mu \mathrm{m}$ ) were taken from postnatal day 13 (P13)-P17 rat pups (Sprague Dawley) using a Leica (Nussloch, Germany) VT1000 tissue slicer. Rats were anesthetized with isoflurane and decapitated, and the brain was dissected out and immersed in ice-cold artificial CSF (ACSF) containing (in mM) 110 choline chloride, $25 \mathrm{NaHCO}_{3}, 25$ D-glucose, $7 \mathrm{MgSO}_{4}, 2.5$ $\mathrm{KCl}, 1.25 \mathrm{NaH}_{2} \mathrm{PO}_{4}, 11.6$ sodium ascorbate, 3.1 sodium pyruvate, and $0.5 \mathrm{CaCl}_{2}$ and bubbled with $95 \% \mathrm{O}_{2} / 5 \% \mathrm{CO}_{2}$. Slices were allowed to recover for $30 \mathrm{~min}$ at $32^{\circ} \mathrm{C}$ in ACSF containing (in $\mathrm{mm}$ ) $127 \mathrm{NaCl}, 2.5$ $\mathrm{KCl}, 1.25 \mathrm{NaH}_{2} \mathrm{PO}_{4}, 25 \mathrm{NaHCO}_{3}, 25 \mathrm{D}$-glucose, $2 \mathrm{CaCl}_{2}$, and $1 \mathrm{MgCl}_{2}$. Then they were transferred to a holding chamber at room temperature. Recording and imaging were started after at least $1 \mathrm{~h}$ of recovery.

Slices were placed in a custom-made recording chamber on the stage of a custom-made two-photon microscope (modified from BX61W; Olympus, Tokyo, Japan) and perfused at a rate of $1-2 \mathrm{ml} / \mathrm{min}$ with ACSF. All recording and imaging experiments were performed at $30-32^{\circ} \mathrm{C}$. The recording pipettes were filled with (in $\mathrm{mM}$ ) 128 potassium gluconate, 10 $\mathrm{NaCl}, 10$ HEPES, 0.5 EGTA, $2 \mathrm{MgCl}_{2}, 4 \mathrm{Na}_{2} \mathrm{ATP}, 0.4 \mathrm{NaGTP}, 15$ phosphocreatine, and 1 calcein. Picrotoxin $(50 \mu \mathrm{M})$ was added in ACSF to inhibit $\mathrm{GABA}_{\mathrm{A}}$ receptor mediated response. Synaptic inputs were stimulated using a glass pipette with $3 \mu \mathrm{m}$ opening positioned at $\sim 20-30 \mu \mathrm{m}$ away from the imaged spines. CA1 pyramidal neurons in the hippocampus were held in current clamp mode throughout the experiments and EPSPs were recorded unless mentioned otherwise. Stimulation at 0.05 $\mathrm{Hz}$ was used to establish baseline synaptic responses and LTD was induced using a low-frequency stimulus (LFS) of $1 \mathrm{~Hz}$ for $15 \mathrm{~min}$. To isolate NMDA receptor mediated EPSPs, $\mathrm{Mg}^{2+}$ concentration in ACSF was lowered to $0.2 \mathrm{~mm}$ and 6-cyano-7-nitroquinoxaline-2,3-dione (CNQX) $(10 \mu \mathrm{M})$ was added to block AMPAR mediated responses. Synaptic responses were recorded with Axopatch 700B amplifier and analyzed with pClamp 9.0 software (Molecular Devices, Sunnyvale, CA). The initial slope of EPSPs $(10-50 \%)$ was used to measure AMPARmediated synaptic responses, whereas the peak amplitude was used to quantify NMDAR responses.

For experiments where responses to both synaptic stimulation and exogenous glutamate application were collected, the same glass pipette was used to electrically stimulate the presynaptic terminals and puff glutamate onto the same dendritic region containing the stimulated synapses. A picospritzer was used for puffing glutamate with air pressure set to $10 \mathrm{psi}$ and duration to $20 \mathrm{~ms}$, repeated every $5 \mathrm{~min}$. The recording pipettes were filled with (in mM) $125 \mathrm{CsMeSO}_{4}, 10 \mathrm{TEA}, 5 \mathrm{NaCl}, 10$ HEPES $\left(\mathrm{Na}^{+}\right.$salt), 4 lidocaine, 1.1 EGTA, 4 ATP $\left(\mathrm{Mg}^{2+}\right.$ salt), 0.3 GTP $\left(\mathrm{Na}^{+}\right.$salt). Neurons were kept under voltage clamp during the entire recording.

Bolus injection. For the experiments shown in Figure 2, bolus loading was used to introduce fluorescent dye (calcein) into neurons (Konur and Yuste, 2004). Whole-cell recording was made at the soma using a patch pipette containing $5 \mathrm{~mm}$ calcein. After 1-3 min of recording, the pipette was withdrawn slowly from the cell body and the neuron was allowed to recover. In neurons that survived this procedure, spines were brightly labeled and the fluorescence was stable for at least 50-80 min after dye loading (supplemental Fig. 1, available at www.jneurosci.org as supplemental material). Imaging started $\sim 15 \mathrm{~min}$ after dye loading. A second patch recording was made on the same neuron with internal solution containing the desired drug or peptide a few minutes after acquisition of the first set of images. The second set of images was acquired immediately after obtaining the second whole-cell recording configuration. This procedure allowed us to obtain a baseline of synaptic response and spine morphology before the introduction of desired drugs or peptides so that their effects could be compared in the same neurons.
Image acquisition. Time-lapse imaging was performed on a custommade two-photon laser scanning system modified from an Olympus Fluoview FV 300, driven by a Chameleon two-photon laser (Coherent, Santa Clara, CA) tuned to $810 \mathrm{~nm}$. Emitted fluorescence scattered at all directions, and was collected by two photomultiplier tubes (PMTs): one above and one beneath the sample plane. The bottom PMT collected fluorescence transmitted through the slice via an oil condenser [numerical aperture (NA), 1.4; Olympus] and the top PMT collected fluorescence reflected from the slice through a water-immersion objective (40×, NA 0.8; Olympus). Signals from both PMTs were electronically summed to form an image. The two PMTs were placed in the optical path and adjusted to obtain the maximal brightness of fluorescence. The intensity of laser power at the entry of the microscope was 30-40 mw and monitored continuously. Experiments were performed in the frame-scan mode.

Imaging procedure was based on our previous work (Zhou et al., 2004). Images were taken every $15 \mathrm{~min}$ at a resolution of $512 \times 512$ pixels per frame, and an average of two was used in some experiments. For each time point, a stack of images covering the entire three-dimensional (3D) range of the spines was taken with a z-step size $\sim 0.5 \mu \mathrm{m}$. Twodimensional projections of 3D image stacks containing dendritic spines of interest were used for display. All displayed images were raw data rather than processed (such as using deconvolution).

Image analysis. Image analysis was performed blind with the person analyzing the images having no knowledge of the identity of the samples during the analysis. Spines were distinguished from filopodia (Zhou et al., 2004) and only spines were analyzed. An automated image analysis software based on Rayburst algorithm was used to quantify changes in spine size (Wearne et al., 2005; Rodriguez et al., 2006). No deconvolution was used before analysis. Images were filtered by blurring with a $3 \times 3 \times$ 3 convolution kernel of equal weights before use of the Rayburst algorithm. This has the effect of improving the signal-to-noise ratio of the data and enhances the function of Rayburst (Rodriguez et al., 2006). From all the sections, the diameter of a spine with the largest crosssectional area was selected and taken as spine size. For mushroom and thin spines, this procedure measured the maximal width of the spine head. For a stubby spine, the width of a spine at halfway between the spine tip and base was taken as its diameter Measurements were performed on all spines in the image field. We found in our previous study that reduction was observed in the diameter, volume and fluorescence intensity of the spine head after LFS (Zhou et al., 2004). Thus, we used the measurement of spine diameter to quantify changes in spine size in this study for simplicity. We have determined that, in our previous work, spine diameters fluctuate around the mean values for $<10 \%$ under resting condition (Zhou et al., 2004). We also measured the fluorescence intensity of the spine heads in a few critical experiments to verify our conclusions based on measurements of the spine diameters. The integrated fluorescence intensity inside a spine head was measured for individual spines at different time points and normalized to the fluorescence intensity of the dendrites from the same image stack to correct for potential changes in excitation (Holtmaat et al., 2005). This fluorescence intensity is expected to be proportional to the accessible spine volume (Holtmaat et al., 2005).

Drugs and peptides. All peptide used were obtained from Coast Scientific (San Diego, CA) according to the published sequence and purified with HPLC. The amino acid sequence of pep $2 \mathrm{~m}$ (or G10,1 mM), which is a segment of the C-terminal region of GluR2, is KRMKVAKNAQ. The D15 peptide $(1 \mathrm{mM})$ corresponds to a stretch of the PRD domain of dynamin (Dynamin 828-42,) and has a sequence of PPPQVPSRPNRAPPG. The S3 (or p-cofilin) peptide $(0.5 \mathrm{~mm})$ has a sequence of MAS(p)GVAVSDGVIKVFN. All chemicals were from Sigma (St. Louis, $\mathrm{MO})$.

Statistical analysis. All data were expressed as a mean \pm SEM. Paired Student's $t$ test was used for time-lapse electrophysiological experiments. Wilcoxon's signed ranks test was used for comparisons between timelapse imaging experiments, and Mann-Whitney U (Wilcoxon's rank sum) test was used for comparison between different conditions for both electrophysiology and imaging experiments. A minimum criterion of $p<0.05$ was used to determined significance. 
$\mathbf{A}_{1}$
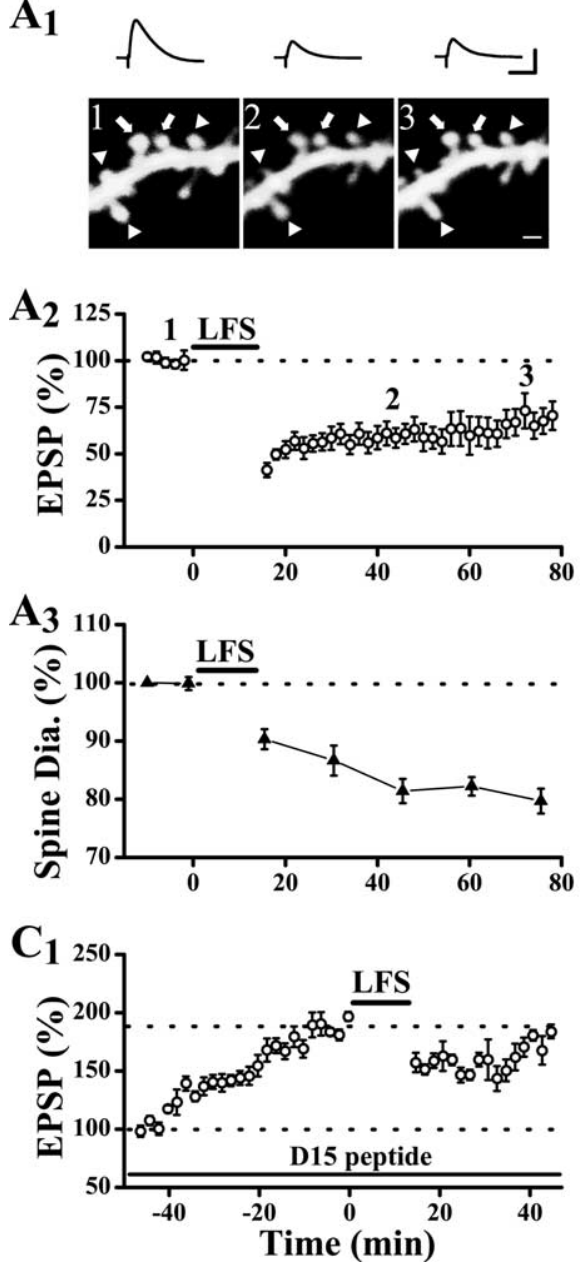

Figure 1. Spine shrinkage and LTD are independent processes. $\boldsymbol{A}_{1}$, Representative example of both EPSPs (average of 5 consecutive traces) and dendritic spines which were monitored simultaneously before, 30 min and 60 min after LFS (1 Hz for 15 min, 900 pulses). Reduction in both spine size and EPSPs were observed after LFS. The numbers on the images correspond to that on the plot in $\boldsymbol{A}_{2}$, indicating when image and voltage traces were acquired. Stable and shrinking spines are indicated by arrows and arrowheads, respectively. $\boldsymbol{A}_{2}$, Plot of normalized slope of EPSPs (mean \pm SEM) showed the expression of LTD after LFS (bar). $\boldsymbol{A}_{\mathbf{3}^{\prime}}$ Population data showed that LFS induced spine shrinkage. $\boldsymbol{B}_{1}$, Another sample experiment showing the absence of spine shrinkage but normal LTD when the $S 3$ (or p-cofilin) peptide was internally loaded into a neuron with the recording patch pipette. Clearly resolved spines that did not exhibit shrinkage were marked by arrows. $\boldsymbol{B}_{2}$, Population results from similar experiments showed that S3 peptide did not block LFS-induced synaptic depression. $\boldsymbol{B}_{\mathbf{3}}$, Population data showed that spine size was not altered (spine diameters at 45 min after LFS were $100.7 \pm 4.4 \%$ of baseline level; $p=0.81$; Wilcoxon's signed ranks test; $n=46$ spines $/ 5$ cells) in neurons loaded with the S3 peptide. $\boldsymbol{C}_{1}$, Internal loading of the D15 peptide led to enhancement of EPSP and inhibition of subsequent induction of LTD (EPSP slopes were $102.3 \pm 8.1 \%$ of plateau level at 30 min after LFS; $p=0.87 ;$ paired $t$ test; $n=7$ cells) with LFS. $C_{2}$, Changes in spine size did not occur during the period of EPSP enhancement, but spine shrinkage occurred after LFS. Calibration: $\boldsymbol{A}_{\boldsymbol{1}}, 10 \mathrm{mV}, 50 \mathrm{~ms} ; \boldsymbol{A}_{\mathbf{2}}, 5 \mathrm{mV}, 50 \mathrm{~ms}$. Scale bars: $\boldsymbol{A}_{\boldsymbol{1}}, \boldsymbol{A}_{\boldsymbol{2}}, 1 \mu \mathrm{m}$.

\section{Results}

Dendritic spines in acute hippocampal slices from postnatal rat pups were labeled using a fluorescent dye calcein. Synaptic responses were evoked by local electrical stimulation of the presynaptic inputs using a glass pipette positioned close to the imaged spines, and the resulting responses were monitored at the soma. We have shown previously that under this experimental configuration, synapses on the imaged spines were effectively activated as revealed by $\mathrm{Ca}^{2+}$ imaging on dendritic spines and these responses contributed to the recorded synaptic responses (Zhou et al., 2004). Because changes in both synaptic physiology and spine morphology were simultaneously monitored, one parameter also served as control for the other to verify the effectiveness of drugs or peptides under certain conditions.
LTD and spine shrinkage can occur independently of each other After LFS ( $1 \mathrm{~Hz}$ for $15 \mathrm{~min}$ ), significant reduction was seen in both synaptic responses (Fig. 1 $1 A_{2}$ ) (EPSP slopes were $62.2 \pm 7.8 \%$ of baseline level at $45 \mathrm{~min}$ after LFS; $p<0.001$; paired $t$ test; $n=15$ cells) and spine diameters (Fig. 1 $A_{3}$ ) (spine diameters were $82.2 \pm 1.6 \%$ of baseline level at $45 \mathrm{~min}$ after LFS; $p<0.01$; Wilcoxon's signed ranks test; $n=76$ spines/8 cells), as has been shown previously (Zhou et al., 2004). We have selected to use spine diameters as the main parameters to quantify changes in spines. To ascertain that we have the necessary power to detect moderate change in diameters (20$30 \%)$, we compared the distribution of measured spine diameters with the measured minimum diameters of $0.1 \mu \mathrm{m}$ fluorescent beads. As shown in supplemental Figure 2 (available at www.jneurosci.org as supplemental material), the majority of spines under control conditions are substantially larger than the beads.

In the first set experiments to address the relationship between spine shrinkage and LTD, we asked whether LTD is affected by the absence of spine shrinkage. To do this, we introduced the synthetic S3 (or p-cofilin) peptide $(0.5 \mathrm{~mm})$ through the recording patch pipette. This peptide contains a phosphorylated Ser-3 site and can compete with the endogenous phosphorylated cofilin as a substrate for protein phosphatases (e.g., Slingshot). This prevents the dephosphorylation and activation of endogenous p-cofilin (Maekawa et al., 1999; Niwa et al., 2002) and inhibits spine shrinkage. Spine shrinkage was absent in neurons loaded with the S3 peptide after LFS (Fig. $1 B_{1}, B_{3}$ ) (Zhou et al., 2004). Despite the lack of spine shrinkage, LTD expressed normally under this condition (Fig. $1 B_{2}$ ) (EPSP slopes were $66.1 \pm 8.1 \%$ of baseline level at $45 \mathrm{~min}$ after LFS; $p<$ 0.001 ; paired $t$ test; $n=8$ cells) and it was not significantly different from control LTD shown in Fig. $1 A_{2}(p=0.34$; MannWhitney $U$ test). This result indicates that LTD does not require spine shrinkage.

Next, we tested whether the converse is true by blocking LTD using internal perfusion of the D15 peptide ( $1 \mathrm{~mm})$. The D15 peptide blocks the interaction between amphiphysin and dynamin, and impairs clathrin-mediated endocytosis (Wigge and McMahon, 1998). We observed an increase in the synaptic responses and blockade of subsequent induction of LTD by LFS, in neurons loaded with the D15 peptide (Fig. $1 C_{1}$ ). Despite the absence of LTD, LFS reduced spine size (Fig. $1 C_{2}$ ) (spine diameters were $85.6 \pm 2.8 \%$ of the baseline level at $15 \mathrm{~min}$ after LFS; 52 spines/ 6 cells; $p<0.05$; Wilcoxon's signed ranks test), and the magnitude of the reduction was similar to that in control neurons after LFS in Fig. $1 A_{3}(p=0.27$; Mann-Whitney $U$ test $)$. There 
was a small but short-lasting depression after LFS in neurons loaded with the D15 peptide, to ensure that spine shrinkage was not caused by this transient depression, we repeated these experiments with higher concentration of the D15 peptide ( $5 \mathrm{~mm}$ ) and observed similar spine shrinkage whereas synaptic responses rapidly returned to baseline level (supplemental Fig. 3, available at www.jneurosci.org as supplemental material). Thus, these results demonstrate that activity-dependent spine shrinkage can occur in the absence of LTD.

We have further examined the distribution of spine diameters before and after LFS in the same set of spines under three conditions: in control neurons, in neurons loaded with the D15 peptide, and in neurons loaded with the S3 peptide (supplemental Fig. 2, available at www.jneurosci. org as supplemental material). There is a clear leftward shift of the entire distribution in control and D15 peptide-loaded neurons, indicating a reduction in spine size. This shift was absent in neurons loaded with the S3 peptide, consistent with a blockade of spine shrinkage. In addition to spine diameters, we also measured fluorescence intensity of spine heads for the experiments shown in Figure 1. Fluorescence intensity of spine heads also exhibited qualitatively similar changes as spine diameter under three conditions (supplemental Fig. 4, available at www. jneurosci.org as supplemental material), confirming our conclusions based on the measurement of spine diameter. Together, our results clearly show that LTD and spine shrinkage are two independent processes that can occur in the absence of the other.

\section{Constitutive trafficking of AMPARs does not alter spine size}

In addition to activity-driven internalization, AMPARs also undergo constitutive trafficking in and out of synapses via endocytosis and exocytosis (Carroll et al., 2001; Song and Huganir, 2002; Bredt and Nicoll, 2003; Collingridge et al., 2004). It is unknown whether this trafficking of AMPARs is accompanied by changes in spine size in the form of rapid expansion and shrinkage. In spines that were imaged under control (nonstimulated) conditions, no persistent changes in spine size were observed (supplemental Fig. 1, available at www.jneurosci.org as supplemental material). However, membrane addition and loss could occur simultaneously or close in time as AMPARs are continuously exocytosed and endocytosed. If this were the case, it would have affected our interpretation of the result in Figure $1 C_{2}$ in that the observed spine shrinkage could reflect a return to baseline after an expansion produced by the sustained blockade of endocytosis by the D15 peptide.

To address this issue, we inhibited one aspect of constitutive trafficking, either endocytosis or exocytosis, and continuously monitored spine size as the remaining unaltered process proceeded. Internal perfusion of N-ehtylmaleimide (NEM; $1 \mathrm{~mm}$ ) through the recording patch pipette blocks soluble $\mathrm{N}$-ethylmaleimide-sensitive fusion (NSF) attachment protein re- ceptor (SNARE)-dependent exocytosis (Luscher et al., 1999). This action of NEM is mediated by its inhibition of NSF protein. Synaptic responses started to decrease $\sim 10$ min after obtaining the whole-cell configuration (Fig. $2 A)(n=7$ cells), and this reduction is caused by continuous internalization of AMPARs through constitutive trafficking (Luscher et al., 1999). Because the time course is fairly rapid, we used a bolus loading method to label spines before introducing NEM to neurons (see Materials and Methods). Only the experiments presented in Figure 2 were performed using the bolus loading method. After identifying a set of spines of interest, we repatched the same neuron with a pipette containing NEM so that we could monitor spine size as NEM took its effect. No significant change in spine size was observed as synaptic responses gradually decreased (Fig. 2B) (spine diameters were $97.6 \pm 1.3 \%$ of control level at $45 \mathrm{~min}$ after second whole-cell recording; $p=0.58$; Wilcoxon's signed ranks test; $n=$ 59 spines/ 6 cells).

NEM has many targets and some of them could play a role in the process under examined. For example, AMPA-induced internalization of AMPARs was enhanced by NEM (Luscher et al., 1999). Thus, we repeated the above experiment using another manipulation to inhibit exocytosis. We loaded the postsynaptic neurons with the light chain of botulinum toxin type B (BoTox; $0.5 \mu \mathrm{M}$ ), a neurotoxin that prevents exocytosis by inactivating the v-SNAREs (Huttner, 1993). This procedure led to a rapid reduction in the basal synaptic transmission (Fig. 2C), although spine 
A
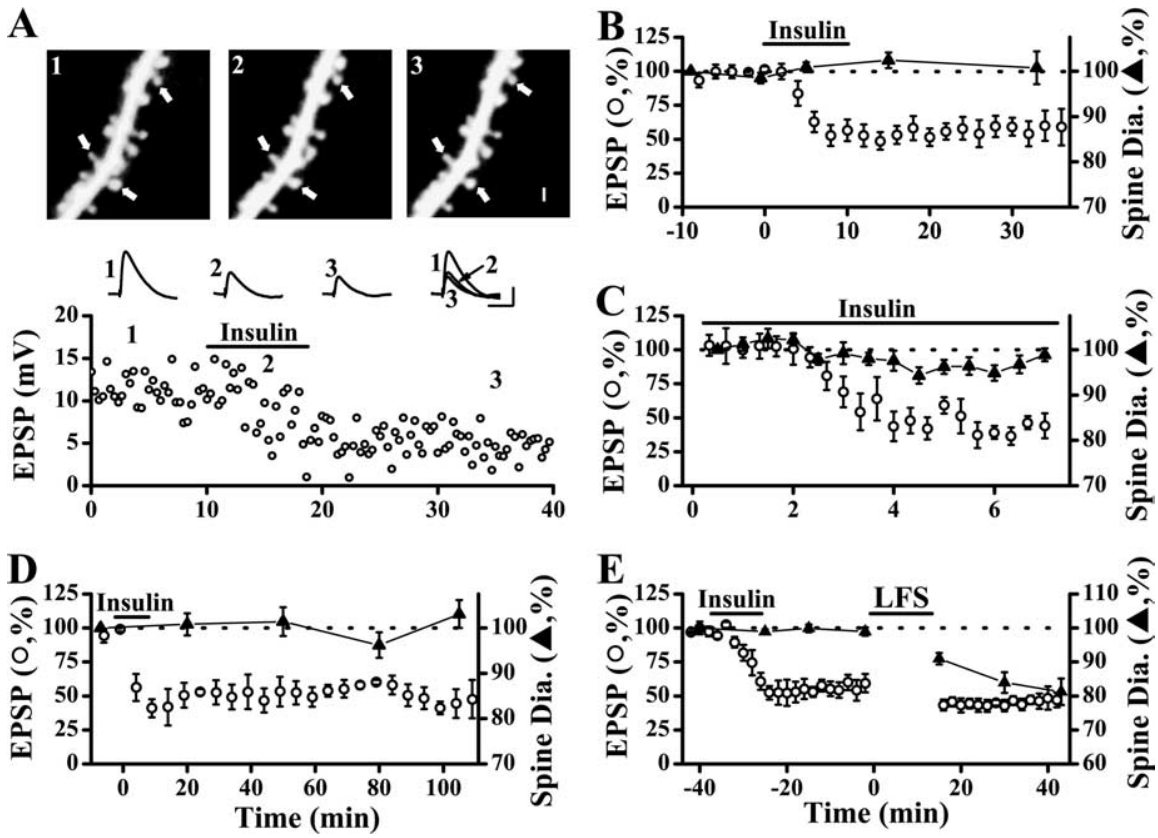

Figure 3. Insulin-induced synaptic depression is not accompanied with spine shrinkage. $\boldsymbol{A}, \mathrm{A}$ sample experiment showing robust reduction in EPSPs and no change in spine size after bath perfusion of insulin. Clearly resolved spines were marked by arrows. $\boldsymbol{B}$, Population data showed no changes in spine size $(\boldsymbol{A})$ at $30 \mathrm{~min}$ after insulin application in the presence of significant synaptic depression (O). $\boldsymbol{C}$, Images were acquired at higher rate (every $30 \mathrm{~s}$ ) to capture potentially rapid or transient changes in spine size. No rapid or transient change in spine size was observed during or shortly after bath application of insulin $(\mathbf{\Delta} ; n=76$ spines/7 cells). On the contrary, rapid and persistent decrease in EPSP slopes were seen after insulin application (O). D, Spine size was stable for $\sim 2 \mathrm{~h}$ after bath application of insulin $(\boldsymbol{\Delta}$; spine diameters were $96.21 \pm 2.8 \%$ of preinsulin level at 90 min after insulin application; $p=0.63$; Wilcoxon's signed ranks test; $n=55$ spines $/ 4$ cells) in the presence of persistent reduction in EPSPs (O). $\boldsymbol{E}$, LFS given at the plateau of insulin-induced synaptic depression did not induce additional reduction in EPSPS (O; EPSP slopes were $94.6 \pm 6.3 \%$ of pre-LFS level at 30 min after LFS; $p=0.15$; paired $t$ test; $n=9$ cells). However, LFS did cause significant spine shrinkage ( $\boldsymbol{\Delta}$; spine diameters were $81.2 \pm 3.8 \%$ of baseline level at 30 min after LFS; $p<0.01$; Wilcoxon's signed ranks test; $n=68$ spines $/ 7$ cells). Calibration: $\boldsymbol{A}, 5 \mathrm{mV}, 50 \mathrm{~ms}$. Scale bar: $\boldsymbol{A}, 1 \mu \mathrm{m}$.

size was unaltered (Fig. $2 D$ ) (spine diameters were $98.9 \pm 2.6 \%$ of pre-BoTox level at $30 \mathrm{~min}$ after loading of BoTox; $p=0.81$; Wilcoxon's signed ranks test; $n=65$ spines $/ 6$ cells). Thus, endocytosis of AMPARs through the constitutive pathway is not associated with reduction in spine size.

Does constitutive exocytosis cause expansion of spines? To address this directly, we again used postsynaptic loading of the D15 peptide to inhibit endocytosis. Again by using bolus labeling, we monitored spine size as the D15 peptide gradually diffused into the spines. Spine size was unaltered (Fig. $2 F)(n=64$ spines/ 6 cells) whereas synaptic responses increased dramatically (Fig. $2 E$ ) ( $n=6$ cells). This lack of changes in spine morphology is unlikely to be caused by the use of whole-cell recording or decline of cell health, because (1) LFS-induced spine shrinkage was reliably observed under the same experimental conditions in control neurons, and (2) LFS still caused spine shrinkage when given at the plateau of the D15 peptide's effect (Fig. $1 C_{2}$ ). Together, the above results strongly indicated that constitutive recycling of AMPARs is not associated with changes in spine size.

\section{Insulin-induced endocytosis of AMPARs is not accompanied by spine shrinkage}

The results presented thus far show that activity-dependent or constitutive internalization of AMPARs occurs in the absence of spine shrinkage. This finding raises the possibility that AMPAR internalization may not be coupled to changes in spine size, regardless of the trigger or underlying signaling mechanism. To determine whether this is the case, we took advantage of the findings that insulin induces a rapid and persistent reduction in synaptic response by stimulating clathrin-mediated internalization of synaptic AMPARs (Beattie et al., 2000; Lin et al., 2000; Man et al., 2000; Wang and Linden, 2000; Huang et al., 2004). The synaptic depression by insulin and LFS-induced LTD occlude each other, indicating that they target the same mobile pool of AMPARs (Man et al., 2000; Wang and Linden, 2000). However, the insulininduced internalization of AMPARs appears to use a different signaling mechanism than that used by LTD, in that it is mostly independent of $\mathrm{Ca}^{2+}$ influx and calcineurin activity (Beattie et al., 2000).

Bath perfusion of insulin $(0.5 \mu \mathrm{M}, 10$ min) led to a rapid reduction in the AMPAR-mediated EPSPs that reached a plateau in 5-10 min (Fig. 3A,B). Despite this large and persistent reduction in synaptic responses, no significant change in spine size was observed (Fig. $3 A, B$ ) (EPSP slopes were $53.7 \pm 1.3 \%$ of preinsulin level, $p<0.001$, paired $t$ test, $n=12$ cells; spine diameters were $100.7 \pm 3.6 \%$ of preinsulin level at $20 \mathrm{~min}$ after insulin perfusion, $p=0.69$, Wilcoxon's signed ranks test, $n=89$ spines/10 cells). However, changes in spine size might occur in two possible ways, one as a transient reduction time-locked to the internalization of AMPARs, the other as a delayed change that takes longer time to develop. The former possibility may reflect the internalization of a patch of membrane associated with endocytosis of AMPARs (on the order of few minutes which is much shorter than the interval of our image acquisition), whereas the latter may be homeostatic in nature to keep the ratio of AMPAR number and spine size constant, as seen at naive synapses/spines (Harris, 1999; Nimchinsky et al., 2002; Kasai et al., 2003).

To address the first possibility, we acquired images with a much higher temporal resolution (every $30 \mathrm{~s}$ ). As shown in Figure $3 C$, spine size fluctuated over time which could be caused by rapid motility of spines (Fischer et al., 1998; Dunaevsky et al., 1999), but no synchronized reduction in spine size and EPSP slope was observed. Because insulin-induced synaptic depression is postsynaptic in nature (Man et al., 2000), the time course of synaptic depression reflects the time course of removal of AMPARs from the synapses. Thus, as AMPARs are internalized there is no concomitant reduction in spine size. Next, we monitored EPSPs and spines for $\sim 2 \mathrm{~h}$ after insulin application to examine whether a delayed change in spine size might occur. No significant changes in spine size were observed in clear contrast to the sustained synaptic depression (Fig. 3D). Hence, insulininduced internalization of AMPARs is not associated with spine shrinkage, either a transient or a persistent one.

Last, we wondered whether spine shrinkage could still be induced by LFS after the insulin-induced synaptic depression was stabilized. No further depression of EPSPs was seen after LFS (Fig. 3E). However, a significant reduction in spine size was observed, comparable to that observed after LFS in control neurons (Fig. 3E). This result is another demonstration of the dissociation 
between LTD and spine shrinkage. This observation further confirms that the lack of spine shrinkage in response to insulin application was not caused by the inability of spines to morph, but rather that insulin was not the right trigger. Thus, it appears that the $\mathrm{Ca}^{2+}$ influx associated with LFS, which is not required for insulin's effect (Beattie et al., 2000; but see Huang et al., 2004), triggers depolymerization of actin filaments (Okamoto et al., 2004) and leads to reduction in spine size.

\section{Trafficking of AMPARs to the extrasynaptic site does not} cause spine shrinkage

In addition to internalization, another way of reducing the synaptic presence of AMPARs is to move them to the extrasynaptic sites. It has been shown that AMPARs move between synaptic and extrasynaptic sites under resting condition and at accelerated rates with activity (Borgdorff and Choquet, 2002; Tardin et al., 2003). We thus examined what occurs to spine size when AMPARs translocate via this lateral movement. To do so, we took advantage of the known effect of another synthetic peptide, pep2m (or G10). Pep2m blocks the interaction between the GluR2 subunit of AMPARs and NSF (Song et al., 1998; Luthi et al., 1999), and reduces synaptic transmission (Song et al., 1998; Luscher et al., 1999; Luthi et al., 1999). Pep2m also inhibits AMPAR endocytosis by interfering with the binding of the clathrin adaptor AP2 to GluR2 (Lee et al., 2002). Thus, it is thought that pep2m-induced synaptic depression corresponds to AMPAR translocation to extrasynaptic sites. Such AMPARs would not be activated by synaptically released glutamate, but would be expected to respond to exogenously applied glutamate.

To test whether synaptic AMPARs can be driven to extrasynaptic locations by pep $2 \mathrm{~m}$, the same glass pipette was used for both local electrical stimulation (to activate only synaptic receptors) and for puffing glutamate ( $1 \mathrm{~mm}, 10 \mathrm{psi}, 20 \mathrm{~ms}$, to activate both synaptic and extrasynaptic AMPARs) onto the same region of the dendritic field. As shown in Figure 4A, internal loading of pep $2 \mathrm{~m}$ $(1 \mathrm{~mm})$ caused a gradual and persistent reduction in EPSCs (synaptic response) with no significant change in the puff response. This result indicates that pep $2 \mathrm{~m}$ reduces the numbers of synaptic AMPARs without affecting the sum of synaptic and extrasynaptic AMPARs, consistent with the notion that pep2m causes synaptic AMPARs to move to the extrasynaptic sites. Furthermore, LFS given at the plateau of the pep $2 \mathrm{~m}$-induced depression did not cause any additional reduction in synaptic responses (Fig. 4B). This result indicates that the same mobile pool of AMPARs is targeted by LFS and pep2m (Luscher et al., 1999; Luthi et al., 1999).

Noel et al. (1999) showed that surface AMPAR were reduced in pep $2 \mathrm{~m}$ expressing neurons using ELISA. This discrepancy between their and our results could be explained by the level and duration of pep $2 \mathrm{~m}$ present in the neurons. Noel et al. (1999) used an inducible adenoviral vector to overexpress the pep $2 \mathrm{~m}$ peptide, and neurons were infected for a total of $40 \mathrm{~h}$ and induced with doxycycline for $16 \mathrm{~h}$. Conceivably, this might have led to a much longer and probably higher concentration of pep $2 \mathrm{~m}$ in the neurons than did with our acute loading. This suggestion is consistent with the observation of Lee et al. (2002), who also did not observe any effect of expressing pep2 $\mathrm{m}$ on the total surface expression of endogenous AMPA receptors. Lee et al. (2002) used EGFP-peptide fusions for 16-24 $\mathrm{h}$ infection which could have led to a lower and shorter elevation in pep $2 \mathrm{~m}$ level than that by Noel et al (1999).

We next monitored spine size during the pep $2 \mathrm{~m}$-induced run-down of synaptic responses. The baseline spine size was de-
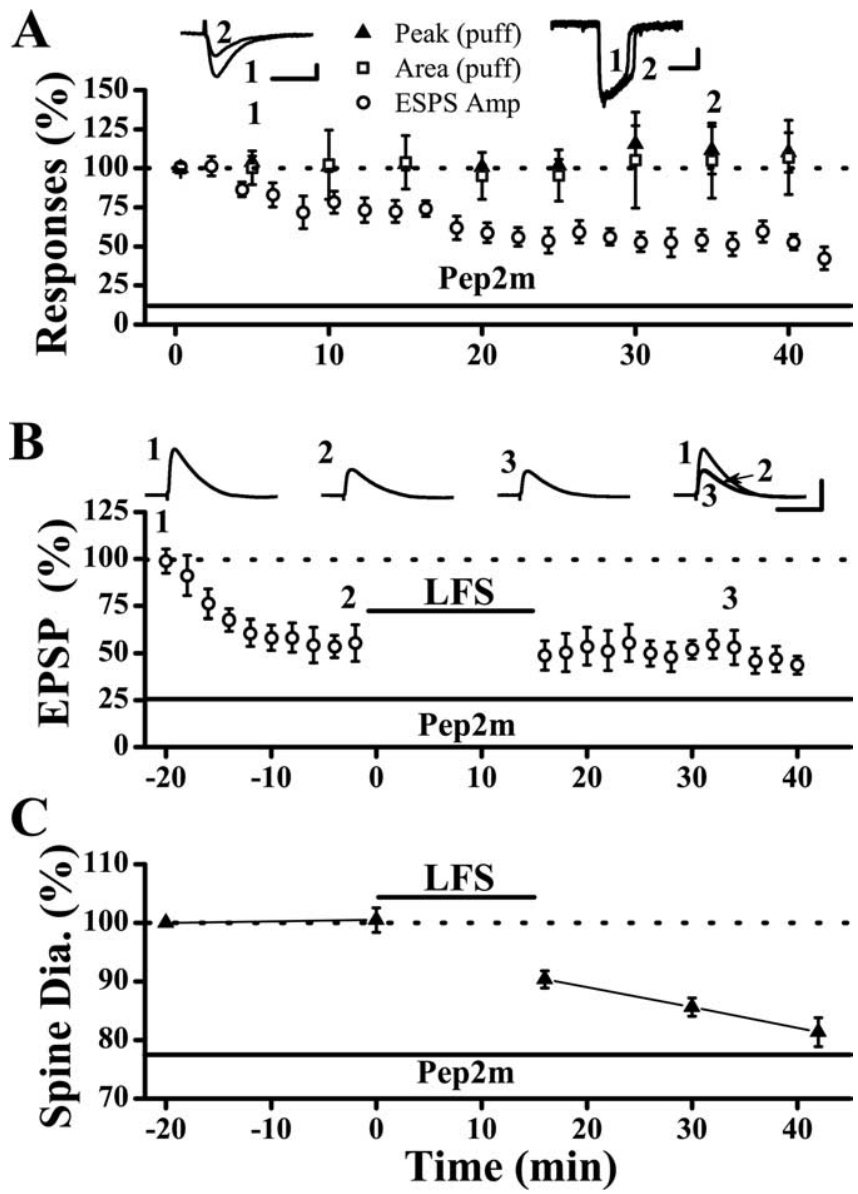

Figure 4. Trafficking of AMPARs induced by pep2m (or G10) does not cause spine shrinkage. $A$, Internal loading of the pep2m peptide caused depression of synaptic responses $(\bigcirc$; peak EPSC amplitudes were $53.9 \pm 6.6 \%$ of baseline level at 35 min after synaptic stimulation; $p<$ 0.001 ; paired $t$ test). However, responses to puffed glutamate was not altered in that both the peak $(\boldsymbol{\Delta} ; 110.2 \pm 15.3 \% ; p=0.49)$ and area $(\square ; 104.6 \pm 24.3 \% ; p=0.37$; paired $t$ test, at 35 min after synaptic stimulation; $n=4$ cells) of glutamate-evoked response were not affected by pep $2 \mathrm{~m}$. Neurons were held in voltage-clamp mode at $-70 \mathrm{mV}$ during these experiments and EPSCs were recorded. $\boldsymbol{B}$, Synaptic depression caused by pep2m occluded the subsequent induction of LTD by LFS (EPSP slopes were $96.9 \pm 10.4 \%$ of the level of the pep $2 \mathrm{~m}$ plateau; $p=$ 0.78 ; paired $t$ test; $n=7$ cells). C, Spine shrinkage did not occur during the rapid synaptic depression but occurred after LFS. Calibration: $\boldsymbol{A}$, left, $50 \mathrm{pA}, 20 \mathrm{~ms}$; right, $100 \mathrm{pA}, 200 \mathrm{~ms} ; \boldsymbol{B}, 10$ $\mathrm{mV}, 50 \mathrm{~ms}$.

termined before the onset of synaptic stimulation, and pep $2 \mathrm{~m}$ should not affect synaptic transmission at this time because its induction of synaptic depression is activity dependent (Luscher et al., 1999). No significant reduction in spine size was observed at the plateau of synaptic depression (Fig. $4 C)(101.8 \pm 3.6 \%$ of baseline at $20 \mathrm{~min}$ after stimulation; $p=0.29$; Wilcoxon's signed ranks test; $n=65$ spines/7 cells), indicating that lateral movement of AMPARs can occur independently of spine shrinkage. However, LFS given at the plateau of pep $2 \mathrm{~m}$-induced depression significantly reduced spine size (Fig. $4 C)(80.5 \pm 2.6 \%$ of baseline at 30 min after LFS; $p<0.05$; Wilcoxon's signed ranks test), and the magnitude of reduction is comparable to that in control neurons. Thus, spine shrinkage is not linked to trafficking of AMPARs via either internalization or lateral movement.

\section{Spine shrinkage associated with NMDAR-LTD}

During LFS, depression of NMDAR-mediated synaptic responses (NMDAR-LTD) occurs in conjunction with the depression of AMPAR-mediated synaptic responses (AMPAR-LTD) (Xiao et 


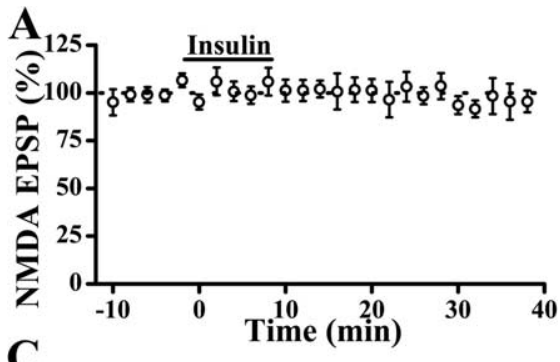

C
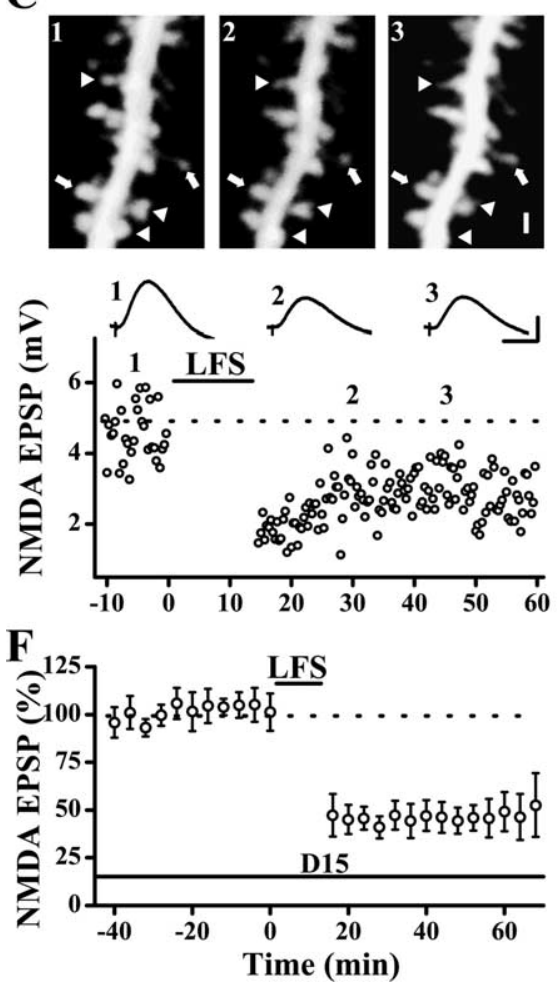
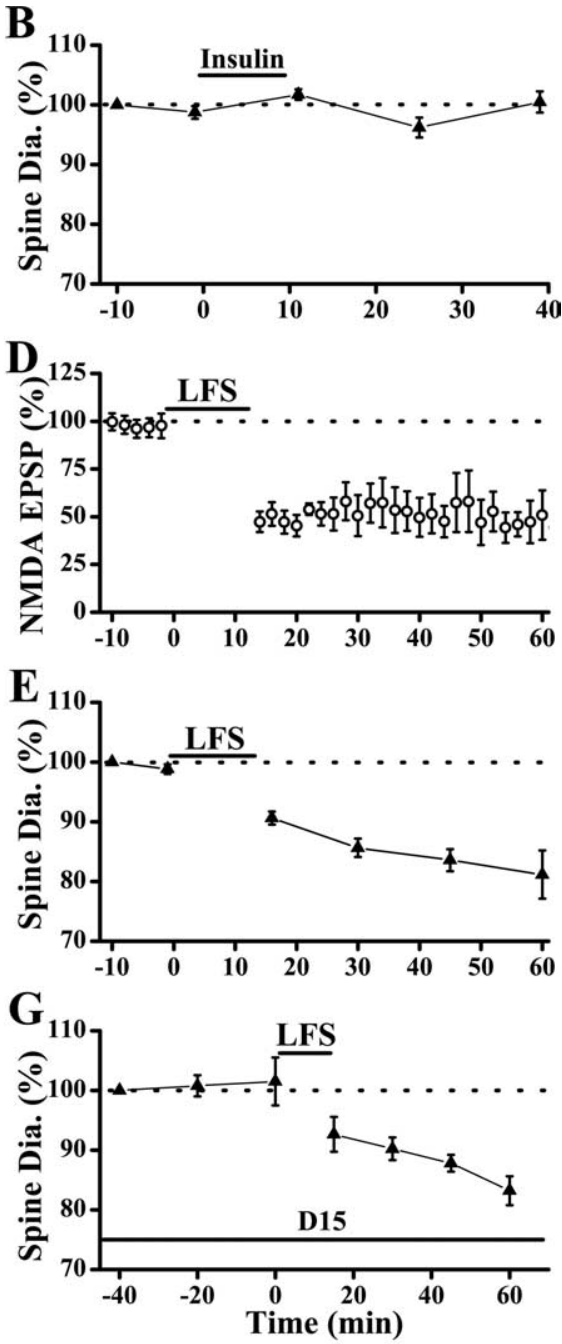

Figure 5. Induction of NMDAR-LTD leads to spine shrinkage. $\boldsymbol{A}$, Bath perfusion of insulin did not alter NMDA-EPSPs, which was isolated using ACSF containing low $\mathrm{Mg}^{2+}(0.2 \mathrm{~mm})$ and CNQX $(10 \mu \mathrm{m})(n=9$ cells). $\boldsymbol{B}$, Spine size was also not altered by bath application of insulin ( $n=75$ spines/7 cells). C, A sample experiment showing that both NMDA-EPSPs and spine size were reduced by LFS. Representative examples of NMDA-EPSPs (average of 5 consecutive traces) are also shown. Stable and shrinking spines are indicated by arrows and arrowheads, respectively. D, Population data showed that LFS induced significant and persistent reduction in NMDAR-EPSPs. $\boldsymbol{E}$, Long-lasting reduction in spine size was also observed after LFS. $\boldsymbol{F}$, Internal loading of the D15 peptide did not affect baseline NMDAR-EPSPs and LFS-induced NMDAR-LTD (peak amplitudes of NMDA-EPSPs were $49.1 \pm 10.2 \%$ of baseline level at 45 min after LFS; $p<0.05$; paired $t$ test; $n=5$ cells). G, Spine size was not altered by internal loading of the D15 peptide, but was reduced after LFS (spine diameters were $83.2 \pm 2.4 \%$ of baseline level at $45 \mathrm{~min}$ after LFS; $p<0.05$; Wilcoxon's signed ranks test; $n=48$ spines/5 cells). This reduction was not different from the controls in $\boldsymbol{E}$ ( $p=0.94$, Mann-Whitney $U$ test). Calibration: C, $2 \mathrm{mV}, 50 \mathrm{~ms}$. Scale bar, $1 \mu \mathrm{m}$.

al., 1994; Selig et al., 1995; Montgomery et al., 2005). This NMDAR-LTD was shown previously to require changes in the cytoskeleton, although it is unknown whether this is equivalent to spine shrinkage (Morishita et al., 2005). Thus, there is a possibility that this NMDAR-LTD may be casually linked to spine shrinkage. If this is the case, then we would expect spine shrinkage to be absent when NMDAR-LTD does not occur. Consistent with this, we found that insulin did not alter NMDAR responses (Fig. 5A) or spine size (Fig. 5B). In these experiments, the EPSPs mediated by NMDARs were isolated by lowering the concentration of $\mathrm{Mg}^{2+}$ in the ACSF (to $0.2 \mathrm{~mm}$ ) and by inhibiting AMPAR using a selective blocker CNQX (10 $\mu \mathrm{M})$ (Selig et al., 1995).

To study the relationship between spine shrinkage and NMDAR-LTD directly, we first examined whether spine shrinkage occurs when NMDAR-LTD was induced in isolation. Stimu- lation of synaptic inputs with LFS led to a large and persistent reduction in spine head size (Fig. 5C,E) (spine diameters were $83.5 \pm 1.8 \%$ of baseline level at $45 \mathrm{~min}$ after LFS; $p<0.001$; Wilcoxon's signed ranks test; $n=87$ spines/ 8 cells), together with NMDAR-LTD (Fig. 5C,D) (the peak amplitude of NMDA-EPSPs were $51.2 \pm$ $10.2 \%$ of baseline level; $p<0.01$; paired $t$ test; $n=7$ cells). We found that this NMDAR-LTD was not affected by internal loading of the D15 peptide (Fig. $5 F$ ), indicating that it is not mediated by clathrindependent endocytosis and could have contributed to spine shrinkage shown in Figure $1 C_{2}$. Spine shrinkage occurred normally in neurons loaded with the D15 peptide after LFS (Fig. 5G).

Although AMPAR-LTD might also occur with NMDAR-LTD, because AMPARLTD does not cause spine shrinkage, the shrinkage we observed would be caused by either expression of NMDAR-LTD or LFS. Thus, we investigated whether NMDARLTD and spine shrinkage share the same signaling events. Our previous work showed that LFS-induced spine shrinkage requires activation of calcineurin but not PP-1 (Zhou et al., 2004). In neurons loaded with cyclosporine A (CsA; $100 \mu \mathrm{M})$, a potent calcineurin blocker, both NMDAR-LTD (Fig. 6A) and spine shrinkage (Fig. $6 B$ ) were inhibited. However, inhibition of PP-1 through postsynaptic loading of oakadaic acid (OA, $1 \mu \mathrm{M}$ ) blocked NMDAR-LTD (Fig. 6C) (NMDAEPSP peaks were $89.7 \pm 18.8 \%$ of baseline level at $30 \mathrm{~min}$ after LFS; $p=0.75$; paired $t$ test; $n=6$ cells) but did not prevent spine shrinkage (Fig. 6D) (spine diameters were $83.2 \pm 1.2 \%$ of baseline level at $30 \mathrm{~min}$ after LFS; $p<0.05$; Wilcoxon's signed ranks test; $n=69$ spines/ 6 cells). These results indicate that NMDAR-LTD and spine shrinkage diverge in the downstream targets and spine shrinkage can occur in the absence of movement of NMDARs. Does NMDAR-LTD require spine shrinkage? NMDAR-LTD was normal in neurons loaded with the S3 peptide (Fig. 6E) (NMDA-EPSP peaks were $57.2 \pm 10.7 \%$ of baseline level at 30 min after LFS; $p<0.01$; paired $t$ test; $n=8$ cells) when spine shrinkage was inhibited (Fig. $6 F$ ), indicating that NMDAR-LTD can occur in the absence of spine shrinkage.

\section{Depolymerization of actin is required for LTD}

Depolymerization of actin filaments is known to occur with LFS (Okamoto et al., 2004). Because one consequence of actin depolymerization, spine shrinkage, is clearly not causally linked to LTD, does depolymerization of actin play any role in LTD at all? To address this question, we blocked depolymerization of actin by internal perfusion of jasplakinolide (Jasp; $2 \mu \mathrm{M}$ ), a potent inhibitor of actin depolymerization. Baseline synaptic transmission was not affected by Jasp (Fig. 7A) (Xiao et al., 2001). How- 
ever, LFS was ineffective in inducing LTD (Fig. 7A) (EPSP slopes were $96.3 \pm 16.0 \%$ of baseline level at $30 \mathrm{~min}$ after LFS; $p=$ 0.68 ; paired $t$ test; $n=8$ cells). This result indicates that actin depolymerization plays some role in the expression of LTD. Internal loading of Jasp also impaired the expression of NMDAR-LTD (Fig. 7C). The effectiveness of Jasp on inhibiting actin depolymerization is confirmed by the lack of changes in spine size after the induction of NMDAR-LTD (Fig. 7B). The fact that Jasp blocked both LTD and spine shrinkage whereas the S3 peptide only impaired spine shrinkage is consistent with Jasp inhibiting the depolymerization of all actin filaments whereas S3 peptide selectively inhibits cofilin targets. Together, our results support that a limited form of actin remodeling that is morphological silent is involved in or even required for the depression of both AMPAR- or NMDARmediated synaptic responses.

\section{Discussion}

In this study, we present strong evidence that modifications of synaptic physiology and spine morphology are independent processes and dissociable. Specifically, trafficking of both AMPARs and NMDARs are not casually linked to the reduction in spine size, regardless of these trafficking being constitutive, activity-driven or chemically induced. However, actin depolymerization, likely triggered by $\mathrm{Ca}^{2+}$ influx during the induction of LTD, is required for both synaptic depression and spine shrinkage. Thus, distinct types of actin remodeling are set in motion with the induction of LTD, and they play different roles in the expression of physiological and morphological modifications associated with LTD.

\section{Dissociation between physiological and morphological modifications}

Our results demonstrate a clear dissociation between spine shrinkage and both AMPAR- and NMDAR-LTD. Morishita et al. (2005) have examined the effect of S3 peptide on AMPAR- and NMDAR-LTD, induced by $5 \mathrm{~Hz} \times 3$ min synaptic stimulation and showed that NMDAR-LTD, but not AMPAR-LTD, was inhibited by the S3 peptide. It is unclear what accounts for the discrepancy between these results on the NMDAR-LTD. One possibility could be that different signaling mechanisms associated with NMDAR-LTD are invoked, because our NMDAR-LTD requires activity of both calcineurin and $\mathrm{PP}-1$ whereas theirs only requires $\mathrm{PP}-1$. Because spine morphology was not examined by Morishita et al. (2005), it remains to be tested whether spine shrinkage occurs with their NMDAR-LTD and what effect the S3 peptide has.

We have extended the dissociation between LTD and spine shrinkage by showing that reduction in the AMPAR-mediated synaptic responses can occur independently of reduction in spine size, in the situations where endocytosis of AMPARs via constitutive trafficking or driven by insulin, as well as trafficking to the extrasynaptic sites induced by the pep $2 \mathrm{~m}$ peptide, do not cause spine shrinkage. In other words, under certain conditions, coor-

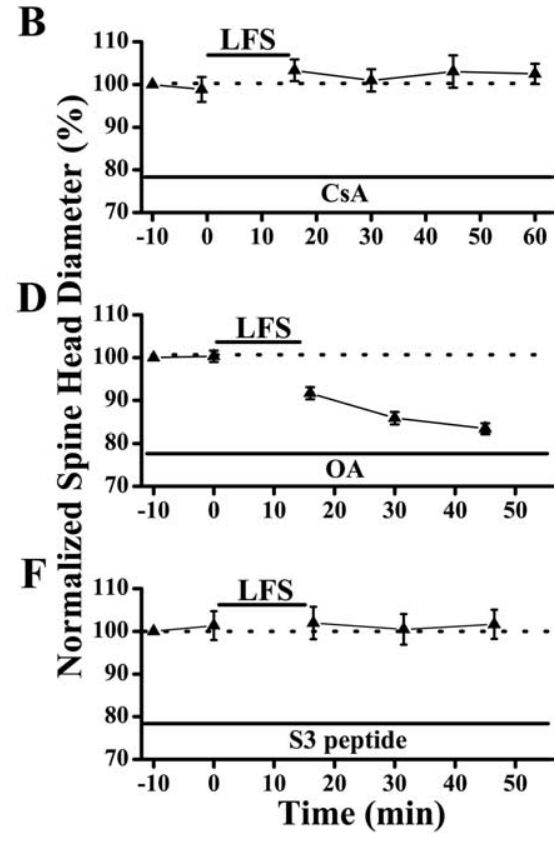

Time (min)

Figure 6. NMDAR-LTD and spine shrinkage are independent processes. $\boldsymbol{A}$, Inhibition of calcineurin signaling by internal loading of CSA, an inhibitor of protein phosphotase 2B, inhibited NMDAR-LTD (NMDA-EPSP peak amplitudes were $95.9 \pm 10.2 \%$ of inhibited by internal loading of the $S 3$ peptide (spine diameters were $101.6 \pm 3.4 \%$ of baseline level at 30 min after LFS; $p>0.05$; Wilcoxon's signed ranks test; $n=63$ spines/ 6 cells).

dinated changes in receptor number and spine size, as seen with LTD, is not preserved. A previous study by Sdrulla and Linden (2007) showed that LTD induction does not lead to changes in spine morphology in the cerebellar Purkinje cells, indicating the independence of these two processes may be further extended to the GABAergic neurons. Hence, it is clear from a cell biology point of view, that the number of synaptic AMPARs and size of spines are controlled by independent mechanisms, at least on a short time scale. It is possible that the matching observed between receptor number and spine size at naive synapses may be a consequence of long-term homeostatic adjustment, occurring on a time scale of hours to days, because we did not observe any changes in spine size $2 \mathrm{~h}$ after insulin-induced LTD had stabilized (Fig. 3D).

What are the functions of spine shrinkage? It remains to be tested whether spine shrinkage contributes to spine elimination seen hours after LFS (Nagerl et al., 2004) or after long incubation with the amyloid $\beta$ peptide (Shankar et al., 2007). Alternatively, the disparities between physiological and morphological modifications might incur different functional consequences. Here, we suggest that coordinated changes in synaptic receptor number and spine size may be important to endow synapses with the capacity to undergo bidirectional changes. In other words, spine shrinkage may be a prerequisite for the reversal of LTD. Consistent with this idea, spine shrinkage is reversed with the reversal of LTD and actin polymerization is required for this reversal (Zhou et al., 2004; Chen et al., 2004; Yang and Zhou, unpublished observation). It is clear that understanding the relationship between synaptic function (number of synaptic receptors) and spine structure (spine size), and how this relationship can be regulated under physiological and pathological conditions, is crucial to our 


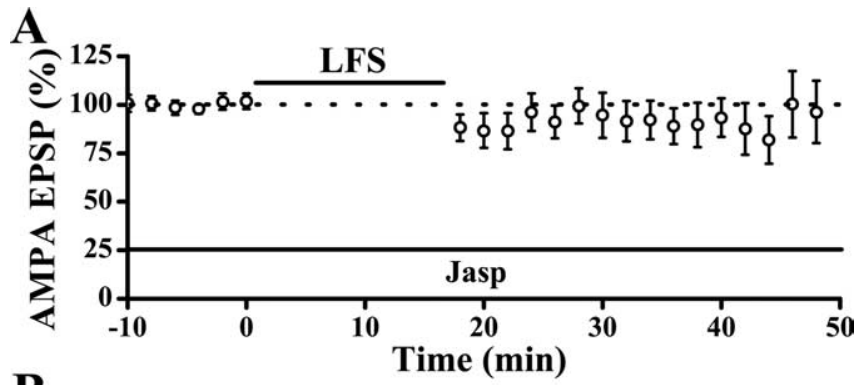

$\mathbf{B}_{1}$
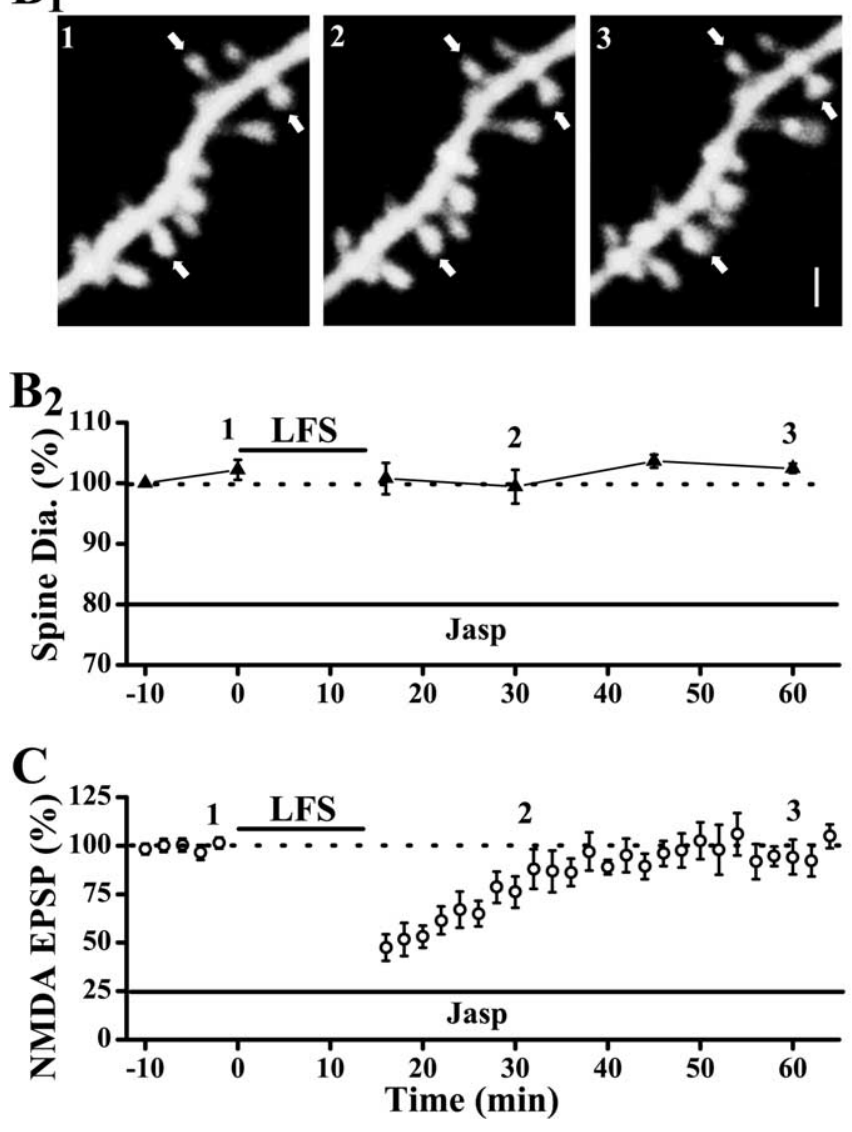

Figure 7. Actin depolymerization is required for both AMPAR-LTD and NMDAR-LTD. $A$, Internal loading of Jasp did not affect basal synaptic transmission but blocked LFS-induced AMPALTD. $\boldsymbol{B}$, Spine shrinkage was abolished by internal loading of Jasp. A sample experiment $\left(\boldsymbol{B}_{\boldsymbol{1}}\right)$ and population data $\left(\boldsymbol{B}_{2}\right)$ showed that spine size was unaltered by LFS in neurons loaded with Jasp (spine diameters were $103.6 \pm 1.1 \%$ of baseline level at 30 min after LFS; $p=0.19$; Wilcoxon's signed ranks test; $n=51$ spines/ 5 cells). Clearly resolved spines were marked by arrows. C, NMDAR-LTD was also absent in neurons loaded with Jasp (NMDA-EPSP peaks were $94.6 \pm 5.1 \%$ of baseline level at 30 min after LFS; $p=0.21$; paired $t$ test; $n=8$ cells). Scale bar, $1 \mu \mathrm{m}$.

comprehension of the function and plasticity of glutamatergic synapses and dendritic spines.

\section{Diverse functions of actin remodeling}

If a reduction in spine size is the only consequence of actin remodeling, we would expect that internal loading of Jasp which inhibits actin depolymerization not to affect LTD. However, the expression of LTD was completely abolished by Jasp. It remains to be determined whether LFS-induced LTD requires activity dependent changes in the actin cytoskeleton or constitutive actin dynamics because both of them are abolished by Jasp (Star et al., 2002). There are at least two possible mechanisms by which actin depolymerization could contribute to LTD: (1) by mediating AMPAR trafficking, (2) by permitting trafficking of key signaling molecules/complex. We will discuss these possibilities in turn.

Previous evidence suggests that AMPARs appear to move to extrasynaptic sites before their internalization (Ashby et al., 2004; Collingridge et al., 2004). It is possible that this lateral movement of receptors may require actin depolymerization. This notion is consistent with our observation that NMDAR-LTD is absent in neurons loaded with Jasp. This NMDAR-LTD appears to require translocation of NMDAR to the extrasynaptic sites because it is unaffected by inhibition of endocytosis (Fig. 5F) (Morishita et al., 2005). This function of actin can be either active in that actin serves as a transport system (Serge et al., 2003) or passive in that they permit diffusion of receptors. In addition to lateral movement, actin may also contribute to endocytosis, as has been shown recently (Merrifield et al., 2005). Actin depolymerization may also permit diffusion of key signaling molecules into spines to gain access to their synaptic targets (Ouyang et al., 2005). Actin filaments are enriched in the spine neck and may act as a barrier keeping large signaling molecules out of the spines (Allison et al., 1998; Kim and Lisman, 1999). LFS-induced actin depolymerization may temporarily remove the barrier allowing molecules, such as PP-1, to diffuse into spines (Morishita et al., 2001). Furthermore, actin depolymerization may allow A-kinaseanchoring protein 79/150 and protein kinase A to leave synapses. As a result, the function of calcineurin and PP-1 could be favored over the kinases, keeping AMPARs dephosphorylated and internalized (Dell'Acqua et al., 2006).

It is possible that distinct populations of F-actin, defined by their subcellular locations and regulation, differentially contribute to neuronal functions (Halpain et al., 1998; Capani et al., 2001; Horne and Dell'Acqua, 2007). Our results provide strong support for such diversity in the actin population. We suggest that at least two principal F-actin populations exist, based on their functions: one to regulate spine size and the other to support the trafficking of receptors or signaling molecules. The actin population that responds to cofilin/ADF activity may be concentrated at the active zone periphery where cofilin was shown to be present (Racz and Weinberg, 2006). If this were the case, it would indicate that spine shrinkage may predominantly target this zone. The location of other F-actin population(s) is unclear and may largely depend on the localization of the molecules being translocated.

There are some outstanding questions raised by the current study: (1) how are AMPARs tethered at synapses when endocytosis is inhibited? A surprising result is that in the D15 peptideloaded neurons, the AMAPR mediated synaptic responses were $\sim 200 \%$ of the resting level while spine size was $\sim 80 \%$ in diameter (or $60 \%$ in volume), after LFS (Fig. 1C). This indicates that far more AMPARs can be fitted into a smaller spine, and these additional receptors are likely to be contained within or near PSDs because they respond to the synaptically released glutamate. Where are these additional AMPARs added and how are they anchored? If spines can accommodate more AMPARs, what limits the number at resting conditions? (2) If diffusion underlies the lateral movement of AMPARs to extrasynaptic sites, is it unidirectional? Alternatively, is there any downstream events making this unidirectional? Trapping internalized AMPARs, such as by dephosphorylation (Brown et al., 2005), may serve such a purpose. (3) Is persistent structural remodeling required for the stable expression of synaptic modification? Can morphological changes serve any meaningful functions unrelated to physiological changes? Although we suggest that spine remodeling may be 
important in maintaining the reversibility of synaptic modification, this has yet to be tested. It also remains to be tested whether spine shrinkage may affect the stability of synapse and spine on a much longer time scale.

In summary, our results demonstrate a clear disconnection between physiological and morphological plasticity, which could be evident even at the level of subpopulations of actin filaments. But yet, remodeling of spines may play at least a permissive role in the expression of synaptic modification.

\section{References}

Allison DW, Gelfand VI, Spector I, Craig AM (1998) Role of actin in anchoring postsynaptic receptors in cultured hippocampal neurons: differential attachment of NMDA versus AMPA receptors. J Neurosci 18:2423-2436.

Ashby MC, De La Rue SA, Ralph GS, Uney J, Collingridge GL, Henley JM (2004) Removal of AMPA receptors (AMPARs) from synapses is preceded by transient endocytosis of extrasynaptic AMPARs. J Neurosci 24:5172-5176.

Beattie EC, Carroll RC, Yu X, Morishita W, Yasuda H, von Zastrow M, Malenka RC (2000) Regulation of AMPA receptor endocytosis by a signaling mechanism shared with LTD. Nat Neurosci 3:1291-1300.

Borgdorff AJ, Choquet D (2002) Regulation of AMPA receptor lateral movements. Nature 417:649-653.

Bredt DS, Nicoll RA (2003) AMPA receptor trafficking at excitatory synapses. Neuron 40:361-379.

Brown TC, Tran IC, Backos DS, Esteban JA (2005) NMDA receptordependent activation of the small GTPase Rab5 drives the removal of synaptic AMPA receptors during hippocampal LTD. Neuron 45:81-94.

Capani F, Martone ME, Deerinck TJ, Ellisman MH (2001) Selective localization of high concentrations of F-actin in subpopulations of dendritic spines in rat central nervous system: a three-dimensional electron microscopic study. J Comp Neurol 435:156-170.

Carroll RC, Beattie EC, von Zastrow M, Malenka RC (2001) Role of AMPA receptor endocytosis in synaptic plasticity. Nat Rev Neurosci 2:315-324.

Chen Y, Bourne J, Pieribone VA, Fitzsimonds RM (2004) The role of actin in the regulation of dendritic spine morphology and bidirectional synaptic plasticity. Neuroreport 15:829-832.

Collingridge GL, Isaac JT, Wang YT (2004) Receptor trafficking and synaptic plasticity. Nat Rev Neurosci 5:952-962.

Dell'Acqua ML, Smith KE, Gorski JA, Horne EA, Gibson ES, Gomez LL (2006) Regulation of neuronal PKA signaling through AKAP targeting dynamics. Eur J Cell Biol 85:627-633.

Dunaevsky A, Tashiro A, Majewska A, Mason C, Yuste R (1999) Developmental regulation of spine motility in the mammalian central nervous system. Proc Natl Acad Sci USA 96:13438-13443.

Engert F, Bonhoeffer T (1999) Dendritic spine changes associated with hippocampal long-term synaptic plasticity. Nature 399:66-70.

Fischer M, Kaech S, Knutti D, Matus A (1998) Rapid actin-based plasticity in dendritic spines. Neuron 20:847-854.

Halpain S, Hipolito A, Saffer L (1998) Regulation of F-actin stability in dendritic spines by glutamate receptors and calcineurin. J Neurosci 18:9835-9844.

Harris KM (1999) Structure, development, and plasticity of dendritic spines. Curr Opin Neurobiol 9:343-348.

Henley JM (2003) Proteins interactions implicated in AMPA receptor trafficking: a clear destination and an improving route map. Neurosci Res 45:243-254.

Holtmaat AJ, Trachtenberg JT, Wilbrecht L, Shepherd GM, Zhang X, Knott GW, Svoboda K (2005) Transient and persistent dendritic spines in the neocortex in vivo. Neuron 45:279-291.

Horne EA, Dell'Acqua ML (2007) Phospholipase C is required for changes in postsynaptic structure and function associated with NMDA receptordependent long-term depression. J Neurosci 27:3523-3534.

Huang CC, Lee CC, Hsu KS (2004) An investigation into signal transduction mechanisms involved in insulin-induced long-term depression in the CA1 region of the hippocampus. J Neurochem 89:217-231.

Huttner WB (1993) Cell biology. Snappy exocytoxins. Nature 365:104-105.

Kasai H, Matsuzaki M, Noguchi J, Yasumatsu N, Nakahara H (2003) Structure-stability-function relationships of dendritic spines. Trends Neurosci 26:360-368.
Kim CH, Lisman JE (1999) A role of actin filament in synaptic transmission and long-term potentiation. J Neurosci 19:4314-4324.

Kim E, Sheng M (2004) PDZ domain proteins of synapses. Nat Rev Neurosci 5:771-781.

Konur S, Yuste R (2004) Developmental regulation of spine and filopodial motility in primary visual cortex: reduced effects of activity and sensory deprivation. J Neurobiol 59:236-246.

Lee SH, Liu L, Wang YT, Sheng M (2002) Clathrin adaptor AP2 and NSF interact with overlapping sites of GluR2 and play distinct roles in AMPA receptor trafficking and hippocampal LTD. Neuron 36:661-674.

Lin JW, Ju W, Foster K, Lee SH, Ahmadian G, Wyszynski M, Wang YT, Sheng M (2000) Distinct molecular mechanisms and divergent endocytotic pathways of AMPA receptor internalization. Nat Neurosci 3:1282-1290.

Luscher C, Xia H, Beattie EC, Carroll RC, von Zastrow M, Malenka RC, Nicoll RA (1999) Role of AMPA receptor cycling in synaptic transmission and plasticity. Neuron 24:649-658.

Luthi A, Chittajallu R, Duprat F, Palmer MJ, Benke TA, Kidd FL, Henley JM, Isaac JT, Collingridge GL (1999) Hippocampal LTD expression involves a pool of AMPARs regulated by the NSF-GluR2 interaction. Neuron 24:389-399.

Maekawa M, Ishizaki T, Boku S, Watanabe N, Fujita A, Iwamatsu A, Obinata T, Ohashi K, Mizuno K, Narumiya S (1999) Signaling from Rho to the actin cytoskeleton through protein kinases ROCK and LIM-kinase. Science 285:895-898.

Malenka RC, Bear MF (2004) LTP and LTD: an embarrassment of riches. Neuron 44:5-21.

Maletic-Savatic M, Malinow R, Svoboda K (1999) Rapid dendritic morphogenesis in CA1 hippocampal dendrites induced by synaptic activity. Science 283:1923-1927.

Malinow R, Malenka RC (2002) AMPA receptor trafficking and synaptic plasticity. Annu Rev Neurosci 25:103-126.

Man HY, Lin JW, Ju WH, Ahmadian G, Liu L, Becker LE, Sheng M, Wang YT (2000) Regulation of AMPA receptor-mediated synaptic transmission by clathrin-dependent receptor internalization. Neuron 25:649-662.

Matsuzaki M, Honkura N, Ellis-Davies GC, Kasai H (2004) Structural basis of long-term potentiation in single dendritic spines. Nature 429:761-766.

Merrifield CJ, Perrais D, Zenisek D (2005) Coupling between clathrincoated-pit invagination, cortactin recruitment, and membrane scission observed in live cells. Cell 121:593-606.

Montgomery JM, Selcher JC, Hanson JE, Madison DV (2005) Dynamindependent NMDAR endocytosis during LTD and its dependence on synaptic state. BMC Neurosci 6:48-57.

Morishita W, Connor JH, Xia H, Quinlan EM, Shenolikar S, Malenka RC (2001) Regulation of synaptic strength by protein phosphatase 1. Neuron 32:1133-1148.

Morishita W, Marie H, Malenka RC (2005) Distinct triggering and expression mechanisms underlie LTD of AMPA and NMDA synaptic responses. Nat Neurosci 8:1043-1050.

Nagerl UV, Eberhorn N, Cambridge SB, Bonhoeffer T (2004) Bidirectional activity-dependent morphological plasticity in hippocampal neurons. Neuron 44:759-767.

Nimchinsky EA, Sabatini BL, Svoboda K (2002) Structure and function of dendritic spines. Annu Rev Physiol 64:313-353.

Niwa R, Nagata-Ohashi K, Takeichi M, Mizuno K, Uemura T (2002) Control of actin reorganization by Slingshot, a family of phosphatases that dephosphorylate ADF/cofilin. Cell 108:233-246.

Noel J, Ralph GS, Pickard L, Williams J, Molnar E, Uney JB, Collingridge GL, Henley JM (1999) Surface expression of AMPA receptors in hippocampal neurons is regulated by an NSF-dependent mechanism. Neuron 23:365-376.

Okamoto K, Nagai T, Miyawaki A, Hayashi Y (2004) Rapid and persistent modulation of actin dynamics regulates postsynaptic reorganization underlying bidirectional plasticity. Nat Neurosci 7:1104-1112.

Ouyang Y, Wong M, Capani F, Rensing N, Lee CS, Liu Q, Neusch C, Martone ME, Wu JY, Yamada K, Ellisman MH, Choi DW (2005) Transient decrease in F-actin may be necessary for translocation of proteins into dendritic spines. Eur J Neurosci 22:2995-3005.

Racz B, Weinberg RJ (2006) Spatial organization of cofilin in dendritic spines. Neuroscience 138:447-456.

Rodriguez A, Ehlenberger D, Hof PR, Wearne SL (2006) Rayburst sampling, an algorithm for automated three-dimensional shape analysis from laserscanning microscopy images. Nat Protoc 1:2156-2161. 
Sdrulla AD, Linden DJ (2007) Double dissociation between long-term depression and dendritic spine morphology in cerebellar Purkinje cells. Nat Neurosci 10:546-548.

Segal M (2005) Dendritic spines and long-term plasticity. Nat Rev Neurosci 6:277-284.

Selig DK, Hjelmstad GO, Herron C, Nicoll RA, Malenka RC (1995) Independent mechanisms for long-term depression of AMPA and NMDA responses. Neuron 15:417-426.

Serge A, Fourgeaud L, Hemar A, Choquet D (2003) Active surface transport of metabotropic glutamate receptors through binding to microtubules and actin flow. J Cell Sci 116:5015-5022.

Shankar GM, Bloodgood BL, Townsend M, Walsh DM, Selkoe DJ, Sabatini BL (2007) Natural oligomers of the Alzheimer amyloid- $\beta$ protein induce reversible synapse loss by modulating an NMDA-type glutamate receptor-dependent signaling pathway. J Neurosci 27:2866-2875.

Sheng M, Lee HS (2003) AMPA receptor trafficking and synaptic plasticity: major unanswered questions. Neurosci Res 46:127-134.

Song I, Kamboj S, Xia J, Dong H, Liao D, Huganir RL (1998) Interaction of the N-ethylmaleimide-sensitive factor with AMPA receptors. Neuron 21:393-400.

Song I, Huganir RL (2002) Regulation of AMPA receptors during synaptic plasticity. Trends Neurosci 25:578-588.

Star EN, Kwiatkowski DJ, Murthy VN (2002) Rapid turnover of actin in dendritic spines and its regulation by activity. Nat Neurosci 5:239-246.

Tardin C, Cognet L, Bats C, Lounis B, Choquet D (2003) Direct imaging of lateral movements of AMPA receptors inside synapses. EMBO J 22:4656-4665.

Wang YT, Linden DJ (2000) Expression of cerebellar long-term depression requires postsynaptic clathrin-mediated endocytosis. Neuron 25:635-647.

Wearne SL, Rodriguez A, Ehlenberger DB, Rocher AB, Henderson SC, Hof PR (2005) New techniques for imaging, digitization and analysis of three-dimensional neural morphology on multiple scales. Neuroscience 136:661-680

Wigge P, McMahon HT (1998) The amphiphysin family of proteins and their role in endocytosis at the synapse. Trends Neurosci 21:339-344.

Xiao MY, Zhou Q, Nicoll RA (2001) Metabotropic glutamate receptor activation causes a rapid redistribution of AMPA receptors. Neuropharmacology 41:664-671.

Xiao MY, Wigstrom H, Gustafsson B (1994) Long-term depression in the hippocampal CA1 region is associated with equal changes in AMPA and NMDA receptor-mediated synaptic potentials. Eur J Neurosci 6:1055-1057.

Yuste R, Bonhoeffer T (2001) Morphological changes in dendritic spines associated with long-term synaptic plasticity. Annu Rev Neurosci 24:1071-1089.

Zhou Q, Homma KJ, Poo MM (2004) Shrinkage of dendritic spines associated with long-term depression of hippocampal synapses. Neuron 44: $749-757$. 